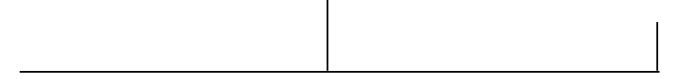

Rev. Latinoam. Psicopat. Fund., São Paulo, v. 12, n. 1, p. 195-208, março 2009

\title{
Medicina, educação e psiquiatria para a infância: o Pavilhão-Escola Bourneville no início do século XX*
}

Renata Prudencio da Silva

Este trabalho analisa a criação do Pavilhão-Escola Bourneville do Hospício Nacional de Alienados no início do século $X X$, primeira instituição brasileira para a assistência a crianças anormais. Destaca o conhecimento então produzido sobre os diagnósticos relativos à infância e sobre o método médico-pedagógico empregado no Pavilhão. Busca-se assim perceber as vias pelas quais a criança se constituiu em objeto da ciência psiquiátrica e das políticas públicas a ela relacionada naquele período.

Palavras-chave: Infância, psiquiatria, medicina, educação

* Trabalho originado de dissertação de mestrado defendida na Pós-Graduação em História das Ciências e da Saúde da Casa de Oswaldo Cruz, em 16 de maio de 2008. Apoio financeiro: Fundação Oswaldo Cruz.

Versão modificada de comunicação apresentada na mesa-redonda "Psiquiatria e psicanálise no Brasil: algumas histórias”, durante o III Congresso Internacional e IX Congresso Brasileiro de Psicopatologia Fundamental (Niterói, RJ, 4 a 7 de setembro de 2008). 
Este trabalho sintetiza a investigação realizada na dissertação de mestrado "Medicina, educação e psiquiatria para a infância: o Pavilhão-Escola Bourneville no início do século XX", apresentada ao Programa de Pós-Graduação em História das Ciências e da Saúde da Casa de Oswaldo Cruz, Fiocruz. Tal pesquisa buscou o entendimento dos fatos que culminaram na construção de conhecimento e prática a respeito da assistência médico-psiquiátrica voltada para a infância brasileira de início do século passado. Seu objetivo foi analisar a criação do Pavilhão-Escola Bourneville, do antigo Hospital Nacional de Alienados no Rio de Janeiro. Tal estabelecimento foi o primeiro a realizar atendimento à criança anormal no Brasil, e tal como seu nome atesta, tinha a pretensão de articular tratamento médico à educação (Silva, 2008). Os pontos que aqui ressalto dizem respeito ao cenário de construção do Pavilhão-Escola Bourneville, ao método de tratamento médico-pedagógico, e à conformação da população atendida nesta instituição.

O período de início do século XX, até fins da década de 1920, pode ser caracterizado pelo entrelaçamento de diversos e divergentes discursos que tinham em comum a meta de construção de um país civilizado. Tal projeto fundamentou construções teóricas e ações sobre a sociedade, que entrelaçaram discursos higiênicos e pedagógicos em um momento em que diferentes especialistas atuaram sobre as crianças em âmbito assistencial e profilático, buscando prevenir possíveis degenerações.

O momento de criação do Pavilhão-Escola Bourneville foi socialmente significativo na medida em que se constituiu em palco de grandes transformações políticas e sociais, bem como de transformações nas relações entre os indivíduos. Tanto a Abolição da Escravidão (1888) quanto a Proclamação da República (1889) foram eventos essenciais neste contexto, pois criaram terreno para diversos questionamentos, dentre os quais sublinho dois: em primeiro lugar como, a partir da república, superar o antigo, o atraso representado pelo sistema monárquico; e em segundo lugar, como pensar, nesta nova configuração política e social, a inserção da população negra. Tais questionamentos são representativos do imperativo da época, qual seja, a construção de uma nação civilizada, marcando o período das três primeiras décadas do século XX como o de maior produção de teorias e práticas sobre este tema.

Esta análise pôde ser desenvolvida até fins da década de 1920, já que é a partir da década de 1930 que a política pública voltada para a saúde assumiu nova direção, após a assunção de Getúlio Vargas à Presidência da República, com a elaboração da Constituição de 1934, entre outros acon- 
tecimentos que marcaram a época, incluindo-se novas diretrizes para a assistência à infância.

\section{O Pavilhão-Escola Bourneville: sua criação}

O Pavilhão-Escola Bourneville foi a concretização de uma resposta aos muitos protestos e denúncias que vinham, desde fins do século XIX, se abatendo sobre a assistência dada às crianças que se encontravam internadas no Hospício Nacional de Alienados (HNA). Quando da criação do pavilhão de crianças, o HNA já contava com quase meio século de fundação e possuía enorme notoriedade social, sendo objeto de atenção e de debate por parte da sociedade letrada do Rio de Janeiro, através de manifestos na imprensa, de relatórios oficiais e de artigos em periódicos científicos especializados.

Tal notoriedade se constituiu em elemento fundamental na construção do Pavilhão Bourneville, na medida em que esta construção se inseriu em um período de profundas transformações do próprio HNA. Este período de agitação e mudança se iniciou com a direção do médico Pedro Dias Carneiro, de 1897 até 1902, período em que já é possível encontrar registros sobre necessidades de reformas que fariam que o hospício se enquadrasse nos métodos modernos de tratamento da alienação mental. Uma das fontes mais significativas acerca destes fatos eram os relatórios anualmente submetidos pelo diretor do HNA ao ministro da Justiça e Negócios Interiores e que davam conta das atividades, resultados e dificuldades do HNA.

Já em 2 de fevereiro de 1902, o Jornal do Comércio publicou várias denúncias sobre as irregularidades do Hospício na administração de Dias Carneiro, entre as quais a de pensionistas que viviam em promiscuidade com indigentes, a de crianças doentes que andariam junto aos adultos, bem como denúncias sobre a falta de equipamentos e de itens básicos, como lençóis ou mesmo camas para os pacientes (Müller, 1998, p. 70).

Ainda que Dias Carneiro tenha se manifestado, enviando relatório ao ministro e contestando as afirmações dos jornalistas, ele continuou sendo alvo de denúncias e criticado como um "homem fraco, cansado e sem espírito de iniciativa, portanto inadequado para estar à frente do Hospício" (Gazeta de Notícias, 13 de fevereiro de 1902, apud Müller, 1998, p.72). O resultado desta movimentação foi a substituição de Dias Carneiro por Antônio Dias Barros, em 12 de julho de 1902.

A gestão de Dias Barros foi curta e marcada por muita agitação. A situação em que se encontrava o HNA, somada às denúncias públicas que acusavam o almoxarife do hospital de desvio de verbas, bem como a precariedade em que 
funcionava desde seu antecessor, desembocou, ainda em 1902, em uma sindicância na instituição por ordem do ministro da Justiça e Negócios Interiores, J. J. Seabra. A comissão de inquérito foi composta pelo farmacêutico Francisco Manuel da Silva Araújo e pelos médicos Antônio Maria Teixeira e Egídio de Salles Guerra, com a posterior inclusão do alienista Carlos Fernandes Eiras (Lobo, 1997, p. 534).

É importante ressaltar que, antes mesmo de finalizar seus trabalhos, a comissão se manifestou a respeito das condições em que se encontravam as crianças. Propondo urgência para a resolução desta questão, atentavam para o fato de que crianças e adultos viviam misturados e que se encontravam muitas vezes em "completo estado de nudez" (Lobo, 1997, p. 534). De tal modo, se fazia necessária a intervenção imediata sobre o HNA para a remoção das crianças para um outro local, que viria a ser um pavilhão anexo à lavanderia do Hospício.

Ao final da sindicância realizada em 1902, Dias Barros foi demitido, ficando, portanto, na direção do HNA por poucos meses. A partir de sua demissão se iniciou a era Juliano Moreira, nomeado diretor do HNA em 26 de março de 1903, por indicação de Afrânio Peixoto ao ministro J. J. Seabra, permanecendo no mesmo cargo até 1930.

Ainda em 1903, Juliano Moreira solicitou verbas ao governo para que pudesse proceder às reformas necessárias, afirmando a importância de que se implantasse um novo modelo de atendimento às crianças do Hospício, bem como a necessidade da contratação de um médico pediatra que ficasse responsável por este serviço. Tal necessidade foi suprida através do decreto n. 1.132 de 22 de dezembro de 1903, assinado pelo presidente Rodrigues Alves, que reorganizava a assistência a alienados no país, e incluía no corpo médico do Hospício um pediatra: Fernandes Figueira. Segundo o relatório de 1904-1905 de Afrânio Peixoto, em sua gestão interina como diretor do HNA, a referida legislação era a consolidação das propostas e planejamento de Juliano Moreira também no que se referia à assistência e educação dos atrasados e débeis.

\section{O Pavilhão-Escola Bourneville: sua população}

Um segundo ponto a ser considerado é o que discorre sobre a população internada no Pavilhão Bourneville. O conhecimento que travamos sobre estas crianças é principalmente aquele que se depreende dos documentos prontuariais daquela instituição. Tais documentos são capazes de informar tanto sobre diagnósticos quanto terapêuticas, e desse modo nos revelar o posicionamento da ciência médica do período a que se referem, bem como de trazer pistas sobre o pertenci- 
mento social daqueles indivíduos que tiveram suas vidas atravessadas pelo sistema de assistência psiquiátrica da época.

Através dos prontuários observamos o registro das primeiras categorias às quais podemos atribuir um conhecimento psiquiátrico relacionado à infância advindo da prática de uma instituição brasileira. Isso nos permite entender como essas crianças eram percebidas pelos médicos e intelectuais da época, além dos trajetos que elas percorreram no interior da instituição e na sua circulação entre esta e a sociedade. Outro ponto a ser ressaltado em relação às crianças internadas no Pavilhão-Escola Bourneville diz respeito ao seu pertencimento social. A grande maioria das crianças, até a década de 1930, tinha sua classe registrada como D.F., ou seja, Distrito Federal, a partir desta década passaria a ser registrada como indigente. Tratava-se de crianças que não possuíam um responsável por pagar suas despesas no HNA. Sua internação era custeada então pelo Estado, tal como vemos no decreto n. 3244 de 29 de março de 1899:

Art. 94. Os enfermos que, por seus parentes, tutores ou curadores, não puderem contribuir com a quantia correspondente à diária de $4^{\mathrm{a}}$ classe e derem entrada no Hospício mediante donativos em dinheiro ou apólices, ou pensões de montepio dos servidores do Estado, terão, salvo resolução em contrário do Ministro, do qual dependerão tais admissões, o tratamento dos enfermos mantidos pelos Estados ou pelo Distrito Federal.

Em artigo precedente deste mesmo decreto foi fixado que a administração do Distrito Federal pagaria pelos indigentes que ali residissem e "cuja internação for requisitada pela Prefeitura, ou pela Policia da Capital Federal" (Art. 91 do decreto $n .3244$ de 29 de março de 1899).

Como a grande maioria das crianças internadas era registrada ora sob responsabilidade do Distrito Federal, ora como indigentes, seria possível chegarmos à conclusão de que tais crianças não possuíam vinculo familiar. Entretanto, foi possível verificar através da documentação consultada que, apesar de a requisição da internação ser feita pelo chefe de polícia, algumas vezes este a fazia por pedido de algum familiar. Além disso, em uma das fichas utilizadas podemos encontrar o registro da movimentação da criança: quando esta saiu de licença, por quanto tempo, a data de retorno, eventuais transferências entre pavilhões etc. A importância destes registros está no fato de que mostram não o abandono dessas crianças por seus familiares, mas sim periodicamente pedidos de licença, de até seis meses, para continuar o tratamento em casa, ainda que com eventuais retornos à instituição.

Um último ponto a respeito da caracterização dessas crianças diz respeito à variável cor da população internada. Tal como averiguei, dentre os prontuários levantados, houve a ocorrência de um número sempre maior de crianças declaradas brancas, em relação às declaradas pardas ou negras. A importância deste ponto está no fato de que ele contraria boa parte da literatura médica, higienista e principal- 
mente eugenista do período, que afirmava, de modo geral, a inferioridade e tendências degenerativas do negro e de sua periculosidade para a sociedade através da miscigenação e consequente transferência de seus maléficos caracteres hereditários.

Esta é uma questão que pode ser tomada contemporaneamente por diversos ângulos, ressalto então uma interpretação feita por um personagem da época. O médico Henrique Roxo (1877-1969), em seu trabalho Perturbações mentais nos negros do Brasil, de 1904, demonstra estatisticamente que a população internada no pavilhão de observação ${ }^{1}$ do HNA entre os anos de 1894 e 1903, era principalmente de indivíduos brancos, o que, a princípio, contrariaria seus trabalhos até então. Assim, Roxo se implicou interpretar estes números de modo a acordarem com suas teorias. Nesse sentido argumentava, nesse mesmo trabalho, que dentre os brancos estariam os estrangeiros e, mais ainda, que os negros eram em menor número no Rio de Janeiro, assim dizendo em defesa de sua teoria que "sendo os pretos em quantidade inferior aos brancos no Rio de Janeiro, reconhecer-se-á que a quota que se verifica pode ser mesmo julgada considerável" (Roxo, 1904, p. 10).

Por considerar interessante a declaração de Roxo sobre o fato de a população negra ser menor do que a branca no Rio de Janeiro no início do século passado, busquei os números levantados pelo recenseamento ${ }^{2}$ realizado em 1890 , documento que poderia servir de base para tal afirmação. A questão se complica no momento em que não sabemos se Roxo, ao falar Rio de Janeiro, se referia ao estado ou ao Distrito Federal. Segundo o referido censo, no Distrito Federal realmente o número de habitantes declarados brancos (327.789) supera o número de não-brancos, ou seja, pretos, caboclos e mestiços (194.862). Entretanto, se nos referirmos ao estado, o número de não-brancos (500.123) superava o número de brancos (376.761), o que revela que a grande maioria de brancos estaria na capital, e de não-brancos no interior do estado. Considerando que o HNA recebia pacientes de todo o país, principalmente no caso do Pavilhão-Escola Bourneville, que se constituía em única opção de instituição do gênero, ainda poderíamos considerar os números em relação à República, onde averiguamos que de um total de

1. O Pavilhão de Observação foi criado através do artigo 26 do decreto no 896 de 26 de junho de 1892, seu funcionamento era em um prédio anexo ao HNA. Funcionava como porta de entrada da instituição, sua finalidade era de ser o local onde se identificariam e classificariam as doenças mentais, ficando ainda sob a responsabilidade do lente da Clínica Psiquiátrica e de Moléstias Nervosas da Faculdade de Medicina do Rio de Janeiro, no caso o médico Henrique Roxo.

2. As informações sobre os censos de 1872 e 1890 podem ser encontradas no site do Centro Brasileiro de Análise e Planejamento: www.cebrap.org.br 
7.237.934 homens, 4.001.201 não eram brancos e de um total de 7.095.981 mulheres, 4.031 .596 não eram brancas, o que é o mesmo que dizer que do total de 14.333.915 habitantes da República em 1890, pouco mais da metade (8.032.797) não eram brancos.

Ainda segundo os prontuários do Pavilhão-Escola Bourneville consultados, observa-se que em quatro décadas os diagnósticos variaram em torno de aproximadamente quinze categorias, sendo os mais recorrentes os de idiotia, paralisia, epilepsia, imbecilidade e os quadros de degeneração. O diagnóstico mais frequente era, com vantagem, o de idiotia. Sua importância para a história do que viria a ser uma psiquiatria infantil precisa ser ressaltada, pois foi com a afirmação da possibilidade de um tratamento/educação das crianças idiotas que se asseverou a distinção entre o cuidado destas e o tratamento dispensado aos adultos, possuidores de diagnósticos diferenciados. A relevância desse diagnóstico está no fato de ele estar na base de afirmação da possibilidade de um tipo de cuidado para com aquelas crianças por muito tempo consideradas intratáveis.

\section{O Pavilhão-Escola Bourneville: seu método}

No Brasil, o trabalho que Fernandes Figueira se propôs a fazer esteve informado por referências científicas produzidas no contexto francês, expressas no aperfeiçoamento que o dr. Desiré Magloire Bourneville (1840-1909) fizera do processo pedagógico de Séguin.

Edouard Séguin (1812-1880), natural de Clamecy, França, principiou seus estudos de medicina com Jean Itard (1775-1838). Iniciou seus estudos no colégio de Auxerre e os terminou no Liceu Saint-Louis, em Paris. A partir de suas pesquisas, concluiu que o idiotismo não era resultado de uma má-formação do sistema nervoso, mas de um problema causado pelo desenvolvimento mental, concentrando assim os seus esforços na educação de crianças com necessidades especiais, na formação de professores e na criação de instrumentos que viabilizassem a educação, principalmente dos sentidos, das crianças idiotas.

No Brasil, a principal referência para a assistência à criança, entretanto, foi Desiré Magloire Bourneville. Ele nascera em 1840, na França, e se tornara médico alienista, ocupando-se durante toda sua vida de tratar e estudar doenças mentais e nervosas infantis. Foi médico interno em Bicêtre, onde foi nomeado médico-chefe do serviço médico infantil, e na Salpêtrière. Foi também conselheiro municipal de Paris de 1876 a 1883, atuando como um dos principais promotores da laicização dos hospitais parisienses, o que ocorreu em 1878. Fundou a escola para enfermeiros que logo substituíram as comunidades religiosas nos hospitais de 
Salpêtrière e Bicêtre. Quando eleito deputado de Paris, no período de 1883-1889, conseguiu a aprovação de um fundo para a criação de um serviço especial para crianças anormais. Posteriormente, lutou e conseguiu regulamentar a implantação de classes especiais para tais crianças nas escolas francesas, morrendo em Paris, em 1909.

Em seu livro Assistence, Traitement, Educacion des Enfants Idiots et Arrièrés, de 1895, Bourneville afirma que em Bicêtre as crianças eram atendidas juntamente com os adultos, recebendo, desse modo, o mesmo tipo de tratamento. Defendia assim a separação das crianças em relação aos adultos para que as primeiras pudessem ter um tratamento diferenciado dado apresentarem patologias específicas (Müller, 1998, p. 97). A situação de Bicêtre antes de Bourneville se assemelhava, sob este aspecto, à situação do HNA: as crianças misturadas aos adultos, recebendo tratamento de modo indiferenciado. Desse modo, o mesmo método utilizado em Bicêtre para resolver o problema da infância internada serviu como fundamento para que no HNA se resolvesse problema muito semelhante.

Quanto ao método preconizado por Bourneville, tratava-se de uma educação médico-pedagógica que visava à intervenção do mais simples para o mais complexo, "começando pela educação do andar, depois das mãos, da vista, da audição, do olfato, do paladar, da palavra, da higiene pessoal, todos com uso de aparelhos especiais ou objetos diversos. O ensino primário também era ministrado para aqueles menos comprometidos e o ensino profissional para os adolescentes" (Müller, 1998, p. 98).

Com relação aos objetivos dos exercícios são interessantes aqueles que visavam promover a aprendizagem de hábitos cotidianos que pudessem promover algum grau de independência, tais como a aprendizagem de se vestir, se despir e amarrar os sapatos, atividade que exige concentração de qualquer criança. Essa aprendizagem corporal era considerada fundamental para que, em primeiro lugar, a criança angariasse alguma confiança e não dependesse tanto dos cuidados alheios. Em segundo lugar, era necessária também para que pudesse, em seguida, receber a instrução elementar.

O tratamento evoluía de modo a compreender uma instrução elementar com atividades que visavam facultar às crianças a noção de comprimento, de superfície, de sólidos e de cores. Exercícios mais complexos consistiam no treino da fala, da leitura e do desenho, até alcançarem o ensino escolar, através das lições de coisas em geral, nas classes ou nos jardins onde a criança reconheceria um nome ou uma coisa bem como o conjunto de signos que serviria para designá-lo por escrito. Tais atividades variavam conforme o grau de comprometimento atribuído à criança, o que serviria para separá-las em diferentes grupos e submeter cada qual a exercícios específicos. 
Por fim, havia o ensino profissional que era composto por diversas oficinas, tais como marcenaria, costura, sapataria, jardinagem, cestaria, entre outras. Para cada uma dessas oficinas havia um profissional que ficava responsável pelo ensino, bem como pela direção moral. O trabalho era considerado importante pelo produto que gerava e por sua influência moral.

Assim, o método de Bourneville tinha como objetivos ajustar a criança anormal às normas sociais, à aprendizagem de hábitos, da leitura, da escrita e de uma profissionalização. Através das atividades que empregou podemos perceber qual a concepção que tinha sobre a criança: um ser sensível às influências externas e que, por isso, suas condutas poderiam ser modificadas através de atividades ocupacionais.

O importante a destacar é que a recepção desse método pela assistência à alienação mental constituiu-se em um processo que data desde antes da criação do Pavilhão-Escola Bourneville do HNA. Segundo Lobo (1997), em 1844, quando ainda se trabalhava na instalação do primeiro hospital de alienados do país, uma comissão foi indicada pelo provedor da Santa Casa de Misericórdia, o senhor José Clemente Pereira, designando a visita aos principais hospitais da Europa. Segundo a autora (1997), fora Antônio José Pereira das Neves o responsável pela visita aos hospitais franceses, e seu relatório, publicado nos Anais de Medicina Brasiliense em 1848, revelava que aquele país vinha criando cada vez mais espaços para crianças débeis e idiotas em seus hospitais para alienados. Neves observou e registrou os trabalhos de Séguin em relação principalmente aos diagnósticos das crianças internadas em Bicêtre e através de seu relatório é possível perceber a afirmação sobre a ação dos estímulos produzidos pelo meio, de tal modo a assinalar a importância da educação (Lobo, 1997). Dessa forma, vemos a possibilidade de que pela intervenção no meio, através da educação, as características inatas, hereditárias fossem alteradas, inibidas ou mesmo conduzidas.

A construção desse método, que afirmava a educabilidade da criança idiota, se tornaria possível através da reformulação da noção de desenvolvimento e consequentemente daquilo que caracterizava a infância. Dessa forma, os conceitos sobre a criança anormal, que partiam de Esquirol, ancoravam-se em uma noção de desenvolvimento ligada a uma fatalidade biológica, às malformações inatas, permanentes e incuráveis. "A ideia de desenvolvimento não como uma norma, uma lei natural da qual ninguém escapa, mas como uma propriedade que uns possuem e outros não" (Lobo, 1997, p. 493). É desse modo que podemos perceber a diferença da compreensão de desenvolvimento entre o idiota e o demente expressa em Esquirol. Esse autor identificava no louco e no demente os lances de uma história, enquanto os suprimia completamente no caso do idiota, de tal modo que a incurabilidade estaria marcada por esse desenvolvimento enquanto propriedade: "A do demente pelo fim de uma história - é um proprietário que ficou 
pobre. A do idiota, por uma história que ele nunca teve porque já nasceu despossuído" (ibid.).

A partir de Séguin, seria possível ver a noção de desenvolvimento não mais como uma propriedade dos indivíduos, mas como "um processo universal, sujeito às contingências de uma velocidade ou de uma parada" (ibid.). O desenvolvimento se tornaria a norma da infância, enquanto um processo em que poderia advir variações. Lobo afirma assim que Séguin, ao definir a idiotia pelo desenvolvimento e defender um método de educação para os idiotas, fez que se distanciasse a relação entre idiotia e doença, que em Esquirol aparecia na cronicidade e incurabilidade de sua definição de idiotia. Segundo a autora, Séguin teria priorizado o tratamento moral acima das técnicas pedagógicas, posto que a idiotia não significasse apenas uma diminuição ou uma parada do desenvolvimento da inteligência, mas acima de tudo uma supressão da vontade moral.

Partindo da noção de Esquirol acerca da primazia da ordem moral na constituição do indivíduo, Séguin consideraria três funções - atividade, inteligência e vontade - e para estas funções dirigiria seu método, de tal modo que a vontade seria o eixo de dominação das outras duas. A vontade instintiva do idiota, sem o controle da vontade intelectual e moral, é que o impossibilitaria de ser socializado, relegando-o ao mundo da animalidade. Dessa forma a educação, através do método de Séguin, seria responsável por resgatá-lo dessa vontade instintiva e humanizá-lo. Para isso o trabalho educativo deveria ser acima de tudo um trabalho moral.

No Brasil, Fernandes Figueira defendia em seus trabalhos a educação médico-pedagógica para o atendimento da criança anormal, reconhecendo o trabalho árduo, mas acreditando ser possível alcançar melhoras significativas na vida dessas crianças com a educação especial e uma metodologia adequada:

O sistema pedagógico, que Bourneville propagou modificando-o de modo favorável, começa corrigindo de muito baixo as regressões à animalidade, e gradativamente eleva o educando fazendo-o ascender à escola primária e, ainda se possível, a alguma cousa do ensino secundário. (Figueira, 1910, p. 322)

\section{Considerações finais}

Enfim, com relação à construção desta história faz-se necessário ressaltar alguns pontos, dentre os quais, a existência de diferentes atores que, ocupando lugares sociais diferenciados, conclamavam a melhoria e necessidade de uma assistência às crianças anormais, atrasadas, imbecis e idiotas: a imprensa leiga, ministro, diretores do hospício, diretor do Pavilhão-Escola, representante da 
intelectualidade, médicos psiquiatras, chefes de polícia e mesmo familiares dos infantes pobres ou com poucas posses que buscavam tratamento a estes até então incuráveis. Essas vozes, entretanto, não foram uníssonas, no sentido apenas de elogiar os grandes feitos da medicina psiquiátrica e da assistência por ela criada.

O que parece ter sido um discurso uníssono foi a crença na ciência e na assistência por ela desenvolvida e subsidiada pelo poder público. Apesar das dificuldades de diferentes ordens - incluindo-se as relativas ao estágio de conhecimento médico-psiquiátrico da época -, acreditava-se que ciência e assistência pública poderiam promover uma mudança de estatuto às crianças até então incuráveis. Essa crença, mesmo considerando-se os resultados posteriores que possa ter produzido em relação à realidade assistencial e social, parece estar fortemente ancorada num espírito humanista próprio da missão que a ciência médica tomava para si.

Tratava-se aqui da construção de um projeto nacional em que as crianças, cera maleável, eram vistas como elementos fundamentais para a constituição, crescimento e prosperidade de nação. Um projeto de nação que, ao que parece, não era visto como possível de ser bem-sucedido pelos atores sociais já mencionados se não incluísse também as crianças anormais que, desassistidas, poderiam refletir um futuro sombrio para a também jovem nação.

Desse modo, minha perspectiva em relação à história da psiquiatrização infantil é de compreendê-la como uma das faces da construção de um contexto mais ampliado em que se empreendia a estruturação de uma assistência à infância no país. Se por muito tempo essa assistência esteve restrita ao âmbito religioso, com instrumentos como a Roda dos Expostos, o que vemos em fins do século XIX, e principalmente nas duas primeiras décadas do século XX, é o despontar de inúmeras iniciativas em relação às crianças, abandonadas ou não. Os médicos e intelectuais da época acreditavam que essa população infantil necessitava mais do que o auxílio espiritual e levantavam assim a bandeira da construção de uma assistência de cunho científico e não somente religioso e caritativo.

Outro ponto a ser considerado na história da construção de uma assistência à saúde da criança no Brasil foi seu vínculo indissociável com outro campo de conhecimento: a educação. Principalmente no que se refere ao tratamento das crianças assistidas no HNA pudemos verificar o vínculo entre medicina e educação configurado no tratamento médico-pedagógico, predominante nas ações em relação àquelas crianças.

Esse vínculo com a educação, associado à absorção de uma outra noção sobre a criança, tal como vimos - a transformação sobre a noção de desenvolvimento, em que a criança anormal não mais seria tratada como monstro incurável, mas sim indivíduo, moldável e impressionável e por isso passível de melhora -, se 
constituíram nos pilares da construção de uma assistência médico-psiquiátrica infantil no início do século XX.

\section{Referências}

BRASIL. Decreto n. 3244, de 29 de março de 1899. Reorganiza a assistencia a alienados. Disponível em: <http://www.planalto.gov.br >. Acesso em: 5 out. 2007.

Brasil. Decreto n. 1.132 de 22 de dezembro de 1903. Organiza a assistencia a alienados. Disponível em: <http://www.planalto.gov.br >. Acesso em: 5 out. 2007.

Figueira, A. F. Educação médico-pedagógica das crianças atrazadas. Arquivos Brasi-leiros de Psiquiatria Neurologia e Medicina Legal, ano VI, n. 1-2, p. 320-331, 1910.

Lово, L. F. Os infames da história: a instituição das deficiências no Brasil. 1997. 611 f. Tese (Doutorado em Psicologia). Departamento de Psicologia, Pontifícia Universidade Católica do Rio de Janeiro - PUC-Rio, Rio de Janeiro.

MülLER, T. M. P. A primeira escola especial para creanças anormaes no Distrito Federal - o Pavilhão Bourneville do hospício Nacional de Alienados (1903-1920): uma leitura foucaultiana. 1998. 167 f. Dissertação (Mestrado em Educação). Faculdade de Educação da Universidade Estadual do Rio de Janeiro - UERJ, Rio de Janeiro.

Relatório do Hospício Nacional de Alienados apresentado ao Exm. Sr. Dr. J. J. Seabra pelo dr. Afrânio Peixoto (1904-1905), s.n.t.

Relatório do Director do Hospício Nacional de Alienados relativo ao anno de 1905. Rio de Janeiro, Imprensa Nacional, 1906.

Relatório do Hospício Nacional de Alienados relativo ao anno de 1906. RJ - Typ. e Enc. do H. N. de Alienados, 1907.

Roxo, H. Duração dos atos psíquicos elementares nos alienados. Tese apresentada à Faculdade de Medicina e Farmácia do Rio de Janeiro, s.n.t., 1900. . Perturbações mentais nos negros do Brasil. s.n.t., 1904.

SaInt-Yves, I. Aperçu historique concernant l'éducation médico-pédagogique: Itard, Séguin et Bourneville. Thèse de Médecine de Lyon, 1914. Disponível em: <http:// web2.bium.univ-paris5.fr/livanc/?cote=TLYO1914x103\&do=pages $>$. Acesso em: 8 jan. 2008.

Silva, R. P. da. Medicina, educação e psiquiatria para a infância: o Pavilhão-Escola Bourneville no início do século XX. 2008. 180 f. Dissertação (Mestrado em História das Ciências e da Saúde). Casa de Oswaldo Cruz, Fiocruz, Rio de Janeiro. 
(Medicina, educación y psiquiatría para la infancia: el Pabellón Escuela Bourneville en el inicio del siglo XX)

Este artículo tiene como objetivo analizar la creación del Pabellón Escuela Bourneville del Hospicio Nacional en el principio del siglo XX, primera institución brasileña para asistencia de los niños anormales. Se destaca el conocimiento producido sobre diagnósticos relativos a la infancia y el método médico-pedagógico usado en el pabellón. Se busca con ello comprender las formas en las que el niño se constituyó en objeto de la ciencia psiquiátrica y de las políticas públicas en aquel período.

Palabras clave: Infancia, psiquiatría, medicina, educación

(Médicine, éducation et psychiatrie de l'enfance: Le Pavillon-École Bourneville au début du $\mathrm{XX}^{\mathrm{e}}$ siècle)

Cet article analyse la création du Pavillon-École Bourneville de l'Hospice National des Aliénés au début $d u X X^{e}$ siècle, première institution brésilienne pour l'assistance des enfants anormaux. Il met en relief le savoir produit à cette époque, lié d'une part aux diagnostiques sur l'enfance et d'autre part à la méthode médico-pédagogique appliquée par le Pavillon. Il décrit de quelle façon l'enfant est constitué comme objet de la science psychiatrique et des politiques publiques dans cette période.

Mots clés: Enfance, psychiatrie, médecine, éducation

(Child medicine, education and psychiatry: the Bourneville Pavilion-School in the early 20th century)

This paper has the objective of analyzing the first Brazilian institution for working with abnormal children, the Bourneville Pavilion-School, at the National Asylum, which operated during the early $20^{\text {th }}$ century. The knowledge at the time regarding diagnoses of children is summarized, together with the medical-pedagogical methods applied at that institution. The manner in which children became the object of psychiatric science and public policies during that period is also treated.

Key words: Childhood, psychiatry, medicine, education

Citação/Citation: SILVA, R.P. da. Medicina, educação e psiquiatria para a infância: o Pavilhão-Escola Bourneville no início do século XX. Revista Latinoamericana de Psicopatologia Fundamental, São Paulo, v. 12, n. 1, p. 195-208, mar. 2009.

Editor do artigo/Editor: Prof. Dr. Paulo Dalgalarrondo e Profa. dra. Ana Maria G. Raimundo Oda. 
Recebido/Received: 6.2.2009 / 2.6.2009 Aceito/Accepted: 9.2.2009 / 2.9.2009

Copyright: @ 2009 Associação Universitária de Pesquisa em Psicopatologia Fundamental/ University Association for Research in Fundamental Psychopathology. Este é um artigo de livre acesso, que permite uso irrestrito, distribuição e reprodução em qualquer meio, desde que $\mathrm{o}$ autor $\mathrm{e}$ a fonte sejam citados/This is an open-access article, which permits unrestricted use, distribution, and reproduction in any medium, provided the original author and source are credited.

Financiamento/Funding: Pesquisa financiada pela Fundação Oswaldo Cruz - Fiocruz/ Research has been funded by Oswaldo Cruz Foundation.

Conflito de interesses: $\mathrm{O}$ autor declara que não há conflito de interesses/The author declares that has no conflict of interest.

\section{Renata Prudencio da Silva}

Graduada em psicologia pela Universidade Federal Fluminense - UFF (Niterói, RJ, Brasil); mestre em Ciências pela Casa de Oswaldo Cruz - Fiocruz (Rio de Janeiro, RJ, Brasil).

Rua Vereador Maurício de Souza, 77 - Fonseca

24110-539 Niterói, RJ, Brasil

e-mail: renata.prudencio@gmail.com 